\title{
Citizen Research Highlights: Blue Flag Beach is not a Reliable Eco-Label to Protect Bathers in Cape Town
}

\author{
Weimann, E \\ Prof. Edda Weimann, MD, MMED (Paeds, Endo \& Metab), MPH \\ Department of Information Systems, University of Cape Town, South Africa
}

Tel: 27- 794981377Ｅ-mail: edda.weimann@uct.ac.za

Received: August 8, 2018 Accepted: August 21, 2018 Published: November 26, 2018

doi:10.5296/jee.v9i2.13478ＵRL: https://doi.org/10.5296/jee.v9i2.13478

\begin{abstract}
Background: Every day over 50 million liters of raw sewage are pumped into the Atlantic Ocean at several marine outfalls around the Cape Peninsula. They are in proximity to Blue Flag beaches and marine coastal nature reserves. This wastewater disposal poses severe health risks to citizens and recreational bathers. Moreover, sea food is contaminated by germs, pharmaceuticals, chemicals and other toxic substances. Caused by the wastewater pollution the marine ecosystem is under threat and deteriorating. Furthermore, Cape Town experiences recurrent droughts and the wastewater disposal puts additional strain to fresh water resources.
\end{abstract}

Study design: The Blue Flag beach criteria were applied as a framework. A citizen research approach was used. Seawater was analysed daily over two months during high tide at Blue Flag beaches in Cape Town during Blue Flag season. Wind directions were recorded, photo documentation performed, and drone flights were conducted. Wastewater related diseases were reported by an online questionnaire.

Results: The water at Blue Flag beaches in Cape Town is contaminated by E. coli. The drone flights showed that the sewage plume is shifted by wind directions, tides and currents towards the coast and Blue Flag beaches. Skin rashes, ear infections, stomach cramps, diarrhea as well as vomiting were reported by recreational bathers.

Conclusions: The dissemination of sewage and other pollutants are influenced by wind directions and currents. The present sewage disposal into the sea poses a risk to the health of recreational bathers and sea food consumers. The International Blue Flag beach label promotes beaches as major tourist attractions but is not a reliable label indicating the cleanliness of water. Tertiary wastewater treatment plants are mandatory for coastal cities to 
protect the marine environment and recreational bathers. The appropriate recycling of wastewater is required to combat recurrent droughts to mitigate the climate crisis.

Keywords: Wastewater-borne diseases, drought, wastewater treatment, sewage outfalls, Blue Flag Beach, Cape Town beaches

\section{List of abbreviations:}

E. coli (Escherichia coli)

C (Celsius)

\section{Fb (Facebook)}

L (litre)

$\mathrm{ml}$ (millilitre)

m (meter)

USA (United States of America)

SA (South Africa) 


\section{Background}

Over 50 million litres of raw sewage are pumped every day into the Atlantic Ocean at several marine outfalls in Cape Town, Western Cape, South Africa (Green Point, Clifton, Camps Bay and Hout Bay) which are located 1700 meters offshore. The outfalls are in proximity to Blue Flag beaches and operate within protected marine coastal reserves. Shuval outlined the impact of wastewater on the health of the population causing thalassogenic or so called wastewater-borne diseases (Shuval, 2003). In Cape Town the sewage outfalls have no legal mandate since the marine sewage discharge license from the Department of Environmental Affairs has expired in July 2016. On top, the sewage amount being discharged considerably exceeds the permitted limit (CSIR, 2017). Previous research has shown that E. coli levels, the internationally acknowledged marker for sewage pollution, are elevated above the recommended limits (Weimann, 2014) at Clifton beach, Cape Town, a world renowned Blue Flag beach. Although the Blue Flag eco label should protect the public from wastewater-borne diseases (Blue Flag, 2013) Blue Flag beaches in Cape Town are regularly contaminated by sewage as shown by research data and official water monitoring. Despite all evidence, the Blue Flag label is still awarded to these beaches. Since the study was conducted other research and action research has confirmed the findings (Petrik et al., 2017). Furthermore, several petitions and social media have urged the municipality to change the present practice and implement wastewater plants, so far without any success (Bradfield, 2015; Prinsloo, 2015, Hart, 2016). A public platform through citizen research (Bonney et al., 2009; Dickinson, Zuckerberg, \& Bonter, 2010) aims to give impetus to the need for urgent improvement of the marine wastewater disposal.

Even though scientific evidence has recommended lower limits for E.coli (88 cfu/100 ml) and Enterococcus levels (EU, 2009; Lévesque \& Gauvin, 2007) to protect bathers, South Africa still applies higher levels (250 cfu/100 ml) at Blue Flag beaches (Lusher, 1984). The predicted geometric-mean of E. coli concentrations of $176 \mathrm{cfu} / 100 \mathrm{~mL}$ versus $101 \mathrm{cfu} / 100$ $\mathrm{mL}$ would allow 9.4 versus 7.1 gastrointestinal illnesses per 1,000 swimmers (Myers, Metzker, \& Francy, 1993), underlining the higher the E. coli count is, the more elevated is the risk for thalassogenic diseases. Furthermore, high economic losses derive from wastewater-borne diseases (DeFlorio-Barker, Wing, Jones, \& Dorevitch, 2018; Shuval, 2003).

Worldwide marine sewage outfalls and the caused pollution severely impacts on the marine environment, the health of recreational bathers and seafood consumers (Beder, 1992; Shuval, 2003). The effluent is diluted 1:100 with potable water by the municipality which adds an additional burden to a water scarce city that frequently encounters severe droughts (Stuart, 2015). South Africa belongs to the water constrained countries only receiving half the global average of rainfall (Turton, 2015). The conservation and up-to-date management of its limited water resource is vital for a sustainable economy and the health of the population. Cape Town faces economic losses of export goods (Phakathi, 2018) through droughts. Since 2016 the Western Cape and the City of Cape Town is under severe water restrictions (50 1/day per person) and can run out of water in case the dams do not receive adequate winter rain fall. This would force citizens of all age groups to collect their daily $25 \mathrm{l}$ water ration at 
several collection points (Cohen, 2017). Through appropriate water conservation and recycling of effluent, water crises could be avoided (Turton, 2015).

Researchers found high levels of microbiological pollution, metals, pharmaceuticals and common household chemicals in seawater around the Cape Peninsula. Hence, water from desalination plants is not recommended to be used for human consumption (Petrik et al., 2017). Through the bioaccumulation in marine organism chemicals and germs become part of the food chain (Reish, Oshida, Mearns, Ginn, \& Buchman, 2005). Wastewater pollution threatens kelp forests (Bennett et al., 2015) and impacts on the marine environment (Connell et al., 2008), (Falkenberg, Burnell, Connell, \& Russell, 2010). African penguin and Bank cormorant colonies that live in proximity to one of the outfalls in Cape Town have severely declined (CSIR, 2017) over the last years.

Desalination as a way of freshwater creation has a high energy demand which is not a sustainable form of water supply for South Africa that encounters regular load shedding and energy blackouts. Moreover, desalination has a negative environmental impact such as suction of fish and shell fish, etc. (Benaissa, Rouane-Hacene, Boutiba, Guibbolini-Sabatier, \& Faverney, 2017)

To alert the public for the ongoing health and environmental threats through wastewater pollution and expand the scientific evidence we engaged in a citizen science project. Citizen science also known as research being performed by volunteers and lay people adds value to asserting additional information, especially in the field of ecology (Bonney et al., 2009).

\section{Study}

We applied the Blue Flag beach criteria as a guiding framework. A citizen science approach was pursued to engage citizens (members of Water Watch South Africa (SA), Code 4 Africa, Cape Town citizens) and raising awareness.

Subsequently the following research questions were asked: What are the E coli levels at various Blue Flag beaches in Cape Town during high tide? What are the recorded wind directions in relation to E. coli levels and the observed sewage plume from air? Which sewage related diseases are reported by recreational bathers? Does citizen science add valuable information regarding sewage pollution of a coastal city such as Cape Town?

To examine the impact of sewage pollution, daily water testing was done at various sites of Blue Flag beaches in Cape Town. Water testing was performed from Monday to Friday during high tide on four sites of Blue Flag beaches: Camps Bay Pump station, Camps Bay Life Guard, Clifton $2^{\text {nd }}$ beach, Clifton $4^{\text {th }}$ beach) (Fig. 1) during the Blue Flag season. Water was taken $20 \mathrm{~cm}$ beyond the surface in knee deep water, stored in sterile bottles and was instantly transported to the lab by a team member of SA Water Watch. Water was analysed by an internationally acknowledged and validated test for E. coli using membrane filtration (incubation $44,5^{\circ} \mathrm{C}$ for 18 to 24 hours, confirmation by gas and indole production from Tryptone at $44^{\circ} \mathrm{C}$ ) in sea water by Swift Laboratories (Cape Town). 


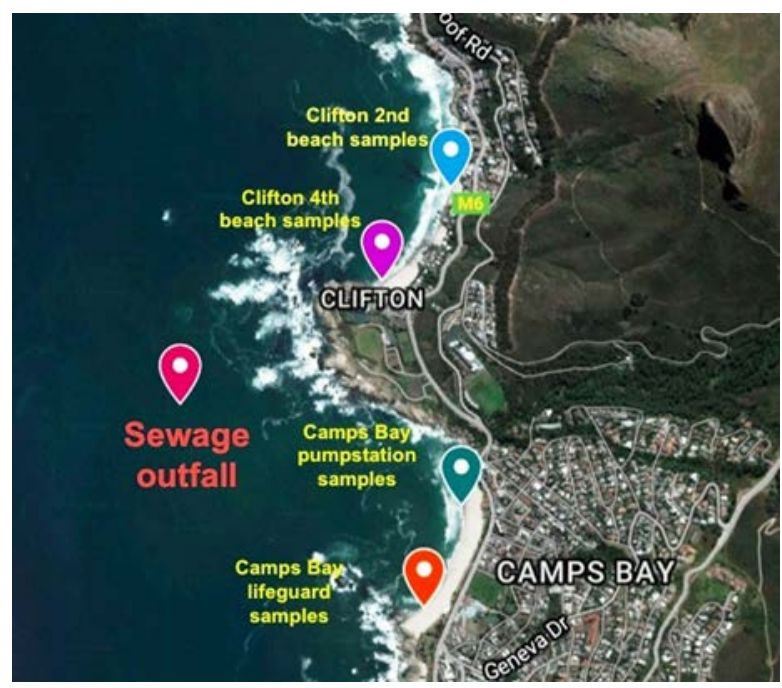

Figure 1. Locations of water sampling

Wind directions were recorded, beaches and sand were photo documented, and drone flights conducted. Public engagement was encouraged via social and other media. Citizen could follow up the project and comment on a Facebook (Fb) page (Water Watch Fb page). An online health questionnaire was published on the Water Watch $\mathrm{Fb}$ page and citizens were asked to participate. Reports and updates were published in local newspapers, TV, broadcasting stations and on social media. The projects were self-sustained through seed and crowd funding by Code 4 Africa Project "Water Watch South Africa”.

The Department of Environmental Affairs (DEA) inshore water quality guidelines, used by the City of Cape Town, are summarised in Table 1.

\begin{tabular}{|c|c|c|c|}
\hline CATEGORY & $\begin{array}{c}\text { ESTIMATED RISK PER } \\
\text { EXPOSURE }\end{array}$ & $\begin{array}{l}\text { ENTEROCOCCI } \\
\text { (Count per } 100 \mathrm{ml})\end{array}$ & $\begin{array}{c}\text { E coli } \\
(\text { Count per } 100 \mathrm{ml})\end{array}$ \\
\hline Excellent & $2.9 \%$ gastrointestinal $(G l)$ illness risk & $\begin{array}{c}\leq 100 \\
\text { (95 percentile) }\end{array}$ & $\begin{array}{c}\leq 250 \\
\text { (95 percentile) }\end{array}$ \\
\hline Good & $5 \% \mathrm{Gl}$ illness risk & $\begin{array}{c}\leq 200 \\
\text { (95percentile) }\end{array}$ & $\begin{array}{c}\leq 500 \\
\text { (95 percentile) }\end{array}$ \\
\hline $\begin{array}{c}\text { Sufficient or Fair } \\
\text { (minimum requirement) }\end{array}$ & $8.5 \% \mathrm{Gl}$ illness risk & $\begin{array}{c}\leq 185 \\
\text { (90 percentile) }\end{array}$ & $\begin{array}{c}\leq 500 \\
(90 \text { percentile) }\end{array}$ \\
\hline $\begin{array}{c}\text { Poor } \\
\text { (unacceptable) }\end{array}$ & $>8.5 \% \mathrm{Gl}$ illness risk & $\begin{array}{c}>185 \\
(90 \text { percentile) }\end{array}$ & $\begin{array}{c}>500 \\
(90 \text { percentile) }\end{array}$ \\
\hline
\end{tabular}

Table 1 . Water quality standards for South Africa

At the time of the study the International Blue Flag program specified an E. coli single-sample limit of $250 \mathrm{cfu} / 100 \mathrm{ml}$ in South Africa whereas lower limits are applied for Blue Flag beaches in Europe (100 cfu/100 ml and below). In the light of the pressurised 


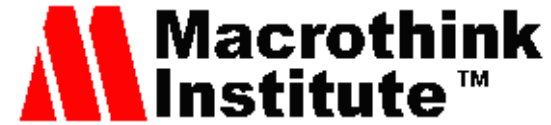

South African public health system that has to carry the additional load of avoidable wastewater related infections, the applied wastewater disposal into the sea is a contentious practice. Related to severe health resource constraints, lower E. coli limits should be in place in SA. This would alleviate the burden for an already overburdened healthcare system with limited resources. Increasingly, several countries, provinces and cities apply stricter E. coli limits to reduce the risks for bathers. The New Hampshire Department of Environmental Services (EPA, 2017) specifies that "E. coli levels at designated swimming beaches should not exceed 88 per 100 milliliter $(\mathrm{mL})$ in any one sample, or exceed a three-sample geometric mean average over a 60 -day period of 47/100mL."

\section{Results}

\section{Water samples}

Water was collected from 21 November 2016 until 16 January 2017 at Blue Flag beaches. Samples were taken at Camps Bay Pump station, Camps Bay Life Guard, Clifton $2^{\text {nd }}$ and Clifton $4^{\text {th }}$ beach. All beaches were monitored during the Blue Flag Season. Sample results are summarized in Figure 2. During the pilot phase (21 November to 15 December 2016), Water Watch SA tested four samples a day, two from Clifton and two from Camps Bay.

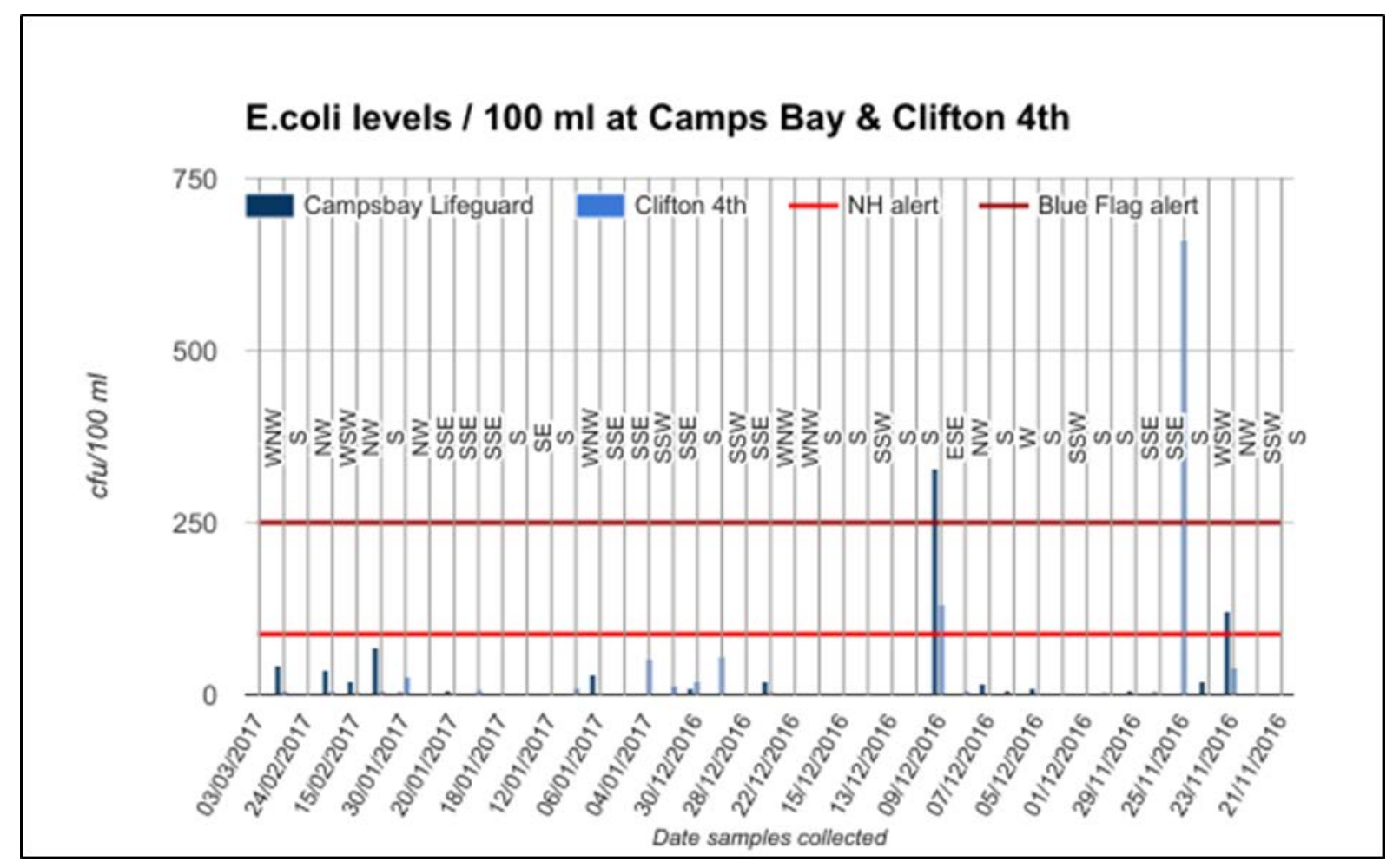

Figure 2. Overview of obtained E. coli levels and wind directions with various safety thresholds (South Africa [brown] versus USA [red]) for recreational water users 


\section{Macrothink

\section{Water testing at Camps Bay beach: Pump Station and Life Guard Hut:}

The highest value for E. coli at the Pump Station was $80 \mathrm{cfu} / 100 \mathrm{ml}$ versus $330 \mathrm{cfu} / 100$ $\mathrm{ml}$ at Camps Bay Life Guard Hut on 9 December underlining that E. coli contamination of beaches varies depending on the location. The wind direction at this time was east-south-east with heavy rain overnight. The beach was flooded, and a substantial amount of green to yellow foam was visible along the beach with marine debris.

On 23 November, a reading of $121 \mathrm{cfu} / 100 \mathrm{ml}$ was obtained in front of the lifeguard hut. The wind direction was north-west and light rain had fallen overnight. On 24 November the wind direction was west-north-west and many dead limpets and other debris were observable on Camps Bay beach. E. coli level were $19 \mathrm{cfu} / 100 \mathrm{ml}$.

\section{Water testing at Clifton $4^{\text {th }}$ and $2^{\text {nd }}$ beach:}

The highest value of E. coli (660 cfu/100 ml) was found on 25 November at Clifton $4^{\text {th }}$ beach. The wind direction was south. Large quantities of foam were visible on Clifton $2^{\text {nd }}$ beach.

On 9 December the sample reading was $130 \mathrm{cfu} / 100 \mathrm{ml}$ on Clifton $4^{\text {th }}$ beach and 60 cfu/ml on Clifton 2nd beach.

In summary, even when low E. coli levels were found on Clifton $2^{\text {nd }}$ beach at the same time, other Blue Flag beaches such as Clifton $4^{\text {th }}$ beach, Camps Bay Lifeguard Hut and Camps Bay Pumphouse had elevated E. coli levels. Clifton $4^{\text {th }}$ beach was frequently contaminated with E. coli (Figure 3). Figure 3 depicts E. coli levels on the four examined Blue Flag beaches. The drone flight conducted on 25 November 2016 displayed that the sewage plume had shifted towards the coastline and the examined Blue Flag beaches.

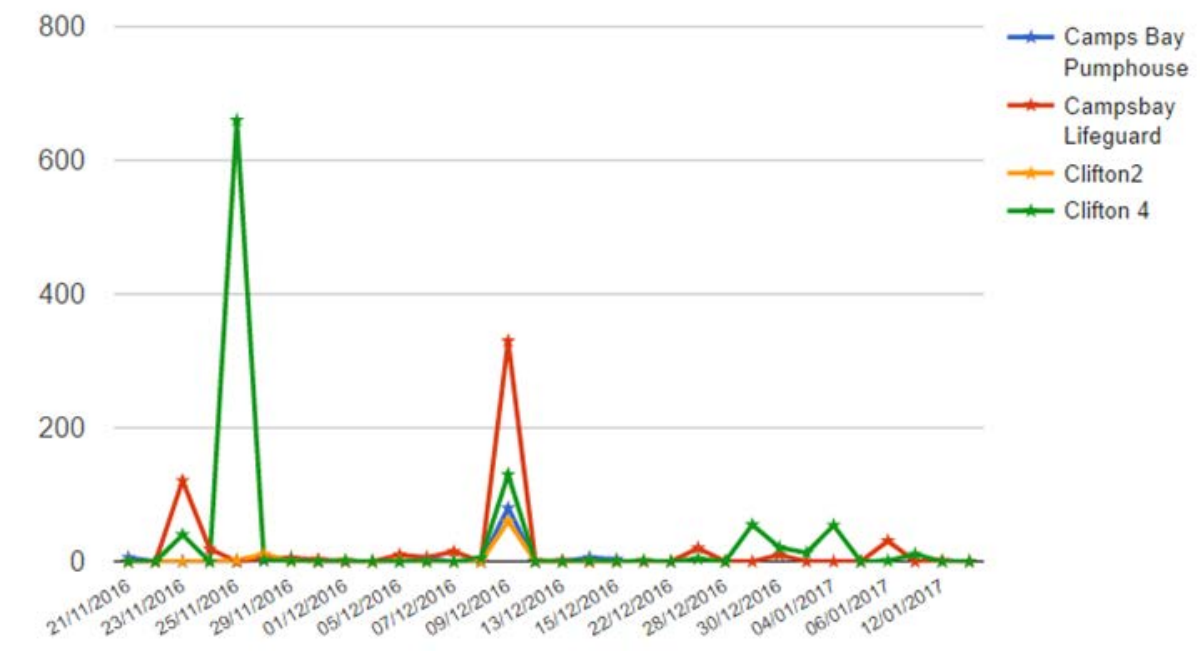

Figure 3. E. coli levels on the examined beaches 


\section{Drone flights}

Drone footage was captured on nine days during the pilot period, providing some excellent footage of the sewage plume on days when it was observable on the surface (Table 2). The plume was visible on the surface on four out of six days when testing took place, of which one the E. coli reading at Clifton $4^{\text {th }}$ beach was $660 \mathrm{cfu} / 100 \mathrm{ml}$ (25 November). At the time the image was taken, the plume was drifting in a westerly direction, away from Camps Bay beach. On that day, the wind was blowing from a southerly direction and on the previous day, from the west.

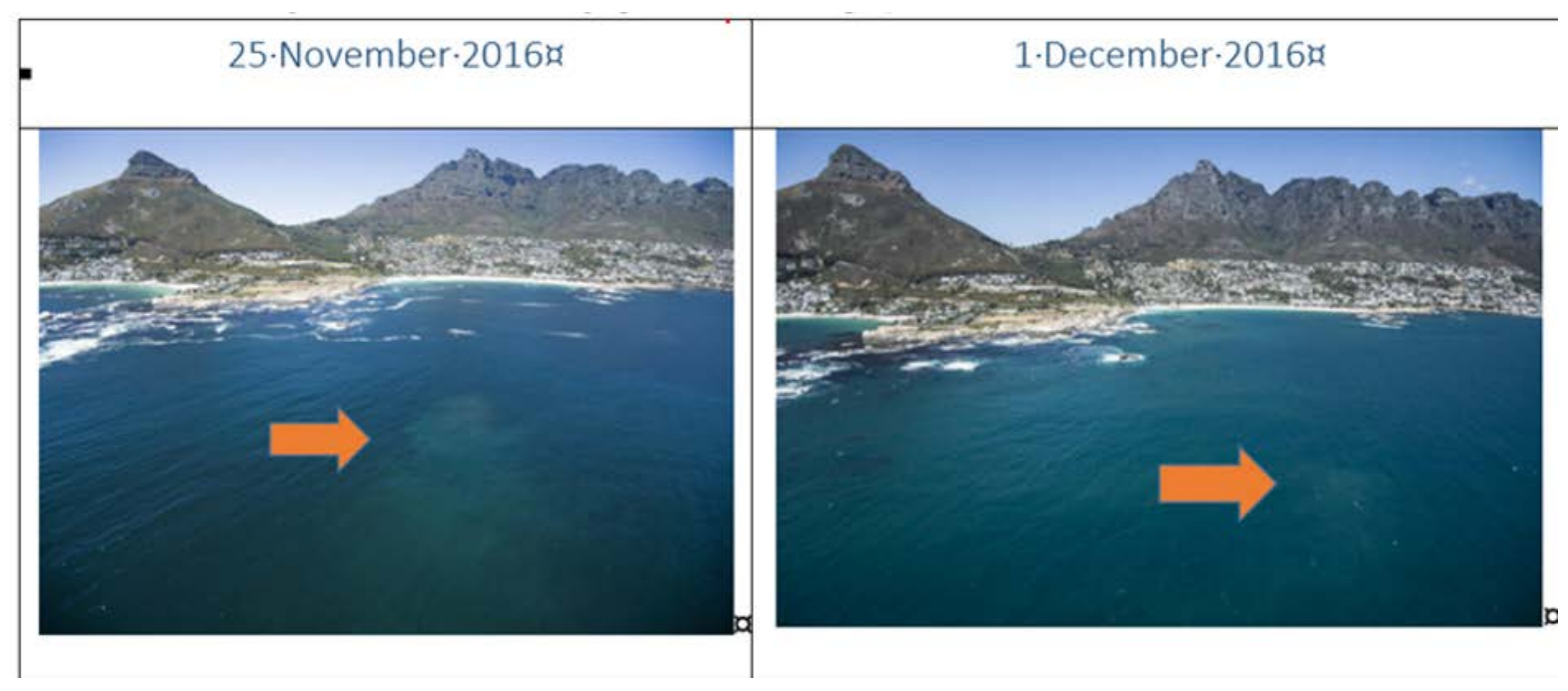

Table 2. Pictures of drone flights capturing the sewage plume

On 1 December 2016, drone images showed the plume apparently drifting in a southerly direction, towards Clifton Beach, against the direction of the wind. The wind on that day (and the previous day) blew from a southerly direction. Samples taken on that day and the following day showed no E. coli on Clifton and Camps Bay.

In some drone images the plume was evident, but there was no proof of a direct correlation between elevated E. coli levels, the visibility of the plume, nor the direction the plume appeared to be drifting. Neither did the wind direction seem to affect apparent drift.

In the conducted drone flights, the sewage was washed back onto the shore on days with westerly wind. While the drone footage provided good images that were useful for media and research purposes, the drone footage also demonstrates that the plume does not always rise to the surface and can drift in various directions. Overall the images could not indicate or predict the presence of E. coli on the beaches.

\section{Heath questionnaire}

Health risks due to sewage pollution so called thalassogenic (wastewater-borne) diseases were further investigated. A questionnaire (Figure 4) was posted on the Water Watch Fb page and advertised through various media. People reported side effects that are related to sewage pollution around the peninsula. Furthermore, swimmers use the shores for long distance 
swimming (e.g. Torpedo swim) (Figure 5). This poses an additional risk as the swimmers are closer to the marine outfalls and are prone to swallow sewage contaminated water.

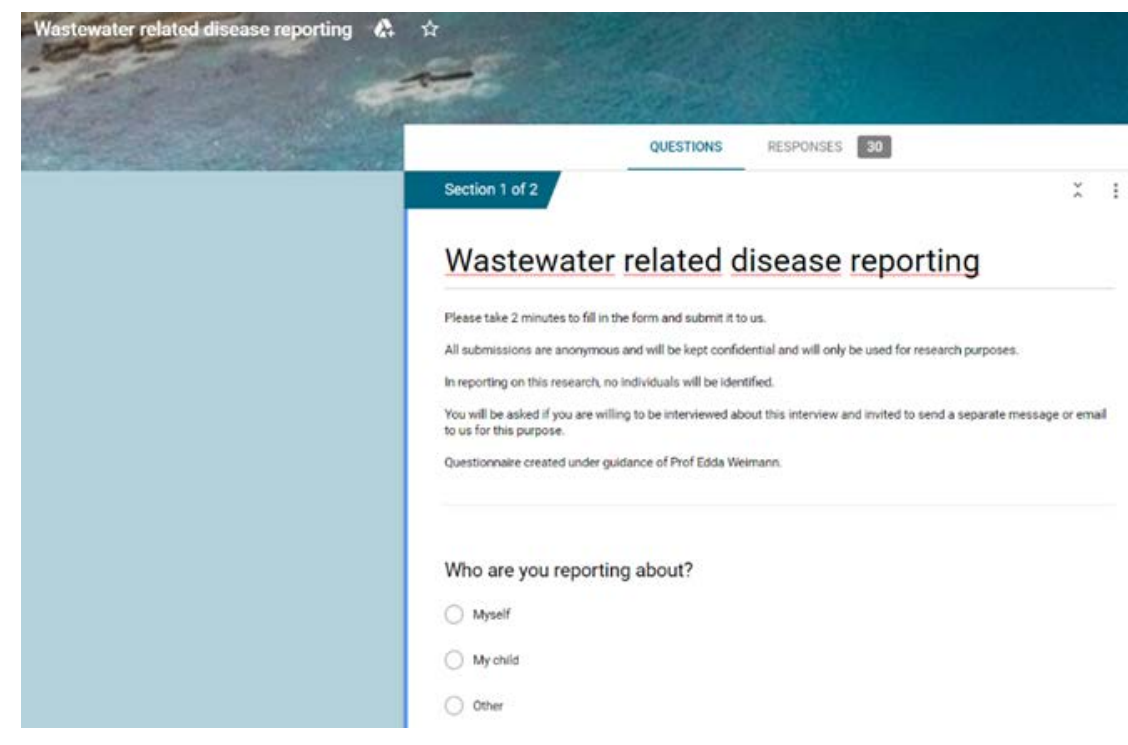

Figure 4. Online questionnaire of wastewater related disease reporting

30 recreational bathers in Cape Town (adults (50\%), toddlers \& children (40\%), elderly people $(10 \%)$ ) responded to the online questionnaire. Exposure to water varied: less than 15 minutes (43\%), between 15 and 60 minutes (23\%), and over 60 minutes (33\%). Participants (60\% male and $40 \%$ females) reported short swim (40\%), surfing (25\%), open water swimming for more than $500 \mathrm{~m}$ (20\%), playing in the sand (10\%), and kayaking (5\%).

Most frequently ear infection (8\%), skin rash, itchy skin and skin infection (22\%), sinusitis (20\%), gastritis, diarrhea as well as vomiting (50\%) were reported. The severity was described as mild (15), moderate (21), and severe (14). The main affected age groups were 18 to 50 years (53\%), 51 to 70 years (23\%), 7-12 years (10\%) and 0-24 months (7\%). One long distance swimmer described that he had faeces in the mouth experiencing later diarrhoea, others suffered severe dehydration with vomiting and needed to be hospitalized. $50 \%$ of the participants reported the symptoms to a medical practitioner.

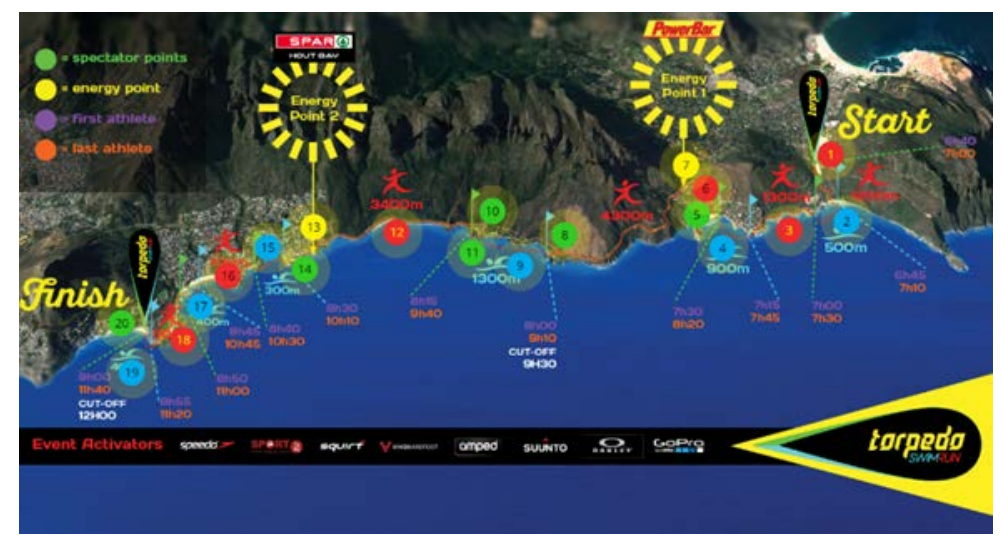

Figure 5. Torpedo swim along marine sewage outfalls 


\section{Macrothink}

Journal of Environment and Ecology

ISSN 2157-6092

2018, Vol. 9, No. 2

\section{Photo documentation}

Each testing day a photo documentation of the four examined Blue Flag beaches were done. The pictures (Table 3) highlight environmental health and safety concerns such as brown foam, dead limpets, flocks of seagulls as a typical sign for wastewater pollution, marine debris, plastic as well as micro-plastic which were found on the beaches although Blue Flag beaches should be regularly cleaned during the Blue Flag season based on their standards.

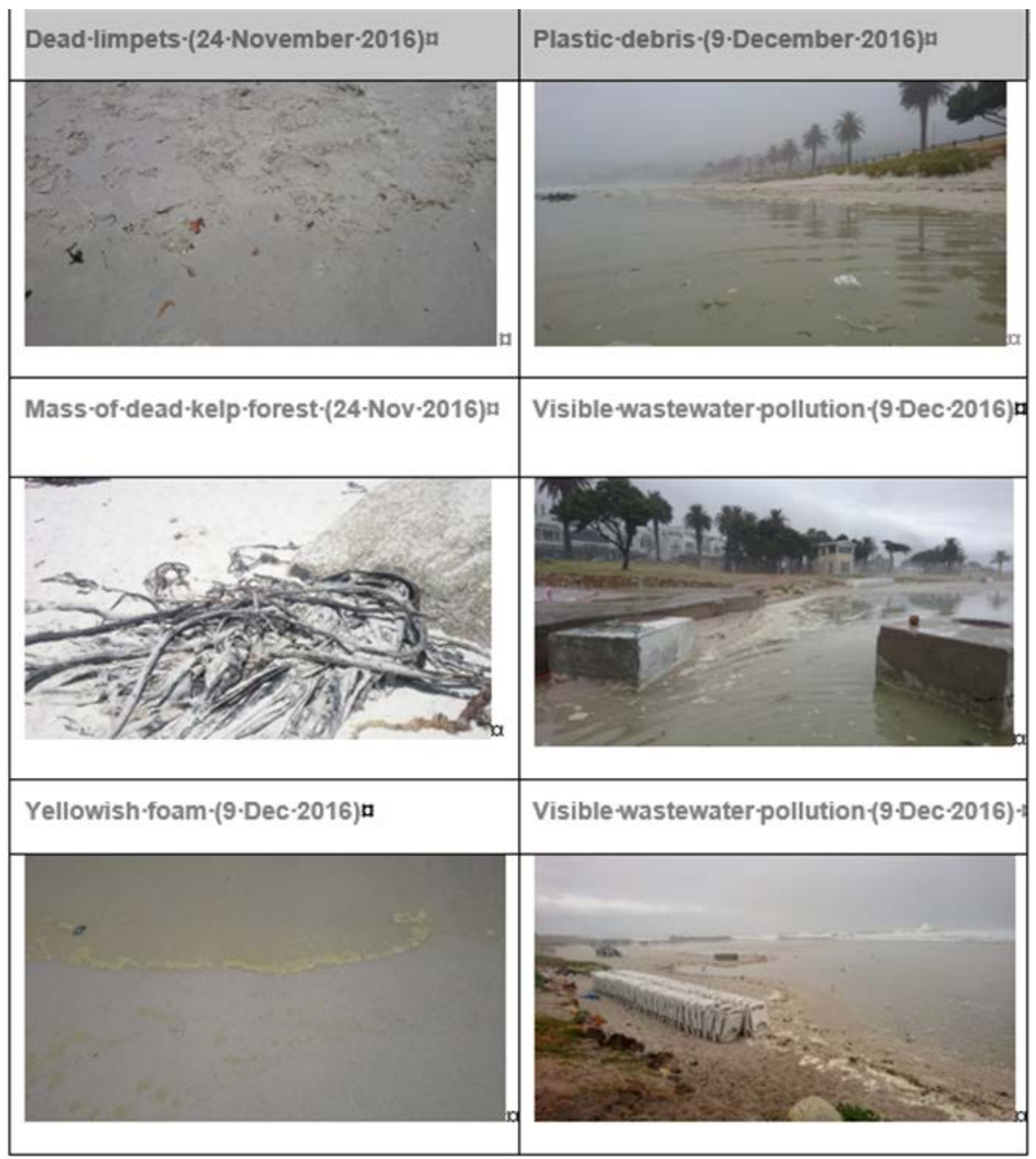

Table 3. Photo documentation of beaches 
Data of the municipal water analyses were displayed at Blue Flag beaches with a delay of several weeks. Frequently they were not presented at all, display was retarded, and specific sampling dates were missing on the board.

\section{Discussion}

Citizen research is a constructive instrument to obtain research data in the field of environmental health and increase existing knowledge (Bonney et al., 2009; Dickinson et al., 2010). In our citizen science study, we could obtain valuable date using awareness tools such as social media, drone flights, online questionnaire and crowd funding.

Our data confirm a high variability of sewage contamination on the examined beaches. When Clifton $2^{\text {nd }}$ beach showed low E. coli levels, others (Clifton $4^{\text {th }}$ beach, Camps Bay Lifeguard and Camps Bay Pumphouse) had elevated levels at the same time of testing. Clifton $4^{\text {th }}$ beach was frequently contaminated with E. coli. The sewage outlets are located approximately 1700 meters offshore (Figure 1). Twice-or one-monthly monitoring of seawater for recreational use as recommended by Blue Flag Beach criteria is not sufficient to avoid health risks for recreational bathers. Our data demonstrate that the examined Blue Flag beaches are diversely affected by sewage pollution. E. coli peaks can occur in between days of official testing. Furthermore, the display of water testing results takes place with significant delay after exposure. Daily online monitoring ("real-time monitoring”) of water quality of beaches as practiced by various cities is mandatory.

Several significantly elevated readings for E. coli occurred with, or soon after, south-westerly to north-westerly wind and, on some occasions, rain. The municipality of Cape Town claims that storm water runoff is responsible for the wastewater pollution and not the wastewater outfalls. This statement cannot be supported by our research data. Rain was in some cases present prior to high E. coli levels but did not occur for all elevated levels.

There is growing evidence that the present practice of sewage pollutions leads to highly polluted seawater in Cape Town (Petrik et al., 2017; Weimann, 2014). Multiple marine factors influence the dissemination of sewage and other pollutants; hence it is difficult to predict the health risks for recreational water users caused by currents and winds. Although E. coli is not detected at one monitoring spot, it does not necessarily mean that the water is entirely safe. The several marine outfalls are close to the shore, protected marine nature reserves and accredited Blue Flag beaches.

The marine sewage outfalls are a health hazard and originates severe health risks to recreational water users. People with compromised immune system (e.g., chronic diseases, small children, elderly, people with renal dysfunction, Tb and HIV infected people, diabetes) are prone to infection when bathing in sewage polluted water. With reference to the reported side effects of bathers it is disputable if the present levels of E. coli (above $250 \mathrm{cfu} / 100 \mathrm{ml}$ ) are appropriate to protect the public. Real-time monitoring via an electronic online App is required for all beaches, at least for Blue Flag beaches, instead of the recommended minimum monthly testing during Blue Flag season. Effluents from rivers and outfalls must be appropriately cleaned before it is pumped into the ocean. 
Other beaches around the peninsula must be monitored as well regarding their water and bathing quality. It can be hypothesized that the contamination in False Bay, Cape Town is even higher than the Atlantic sea shore caused by polluted rivers, several sewage outlets and informal settlements without any sanitation infrastructure (Rebelo, Holmes, Dorse, \& Wood, 2011).

\section{Conclusion}

Despite all evidence, beaches in proximity to marine wastewater outlets are still awarded the Blue Flag status questioning the value of the Blue Flag label as an eco-label. In the light of recent research publications, the criteria of Blue Flag beaches need to be reviewed. The Blue Flag is used as a profile-raising label neglecting the health of recreational water users (Petrik et al., 2017; Weimann, 2014). Daily water and beach monitoring is important and requires appropriate financial resources. At present resulting costs from wastewater-borne diseases are transferred to other cost bearers such as health care providers.

Wastewater pollution poses a severe threat to marine ecosystems and to the health of recreational bathers. The sewage is diluted 1:100 with freshwater putting additional strain onto the municipal water supply. In the light of recurrent droughts and water crises, it is mandatory to establish wastewater treatment plants along the coastline to reduce the health risk for recreational water users and sea food consumers. Based on the amount and level of pollution wastewater plants must have a level three purification process to eliminate chemicals, pharmaceuticals and germs. To maintain Cape Town as a worldwide tourist attraction and provide healthy conditions for recreational bathers these measures are imminent.

\section{Limitations}

The current study has limitations primarily caused by a lack of resources. E. coli as the main predictor for wastewater was analyzed, although other germs, pesticides and chemicals are present in seawater and the sand. Other marine physiological patterns such as swell strength and direction, more localized wind patterns and actual currents could not be examined.

\section{Acknowledgements}

We would like to thank J. Miller for the non-commercial drone flights and equipment, Code 4 Africa for the seed funding and all citizens that volunteered to participate. The input of S. Kromberg from Social Weavers is acknowledged and highly appreciated.

\section{Declaration}

The author declares that there is no conflict of interest. Citizens were informed that the obtained data will be used for research purposes before providing information. Seed funding was received from Code4Africa, later the project was self-sustained through crowd funding. The research project adhered to ethical guidelines of the University of Cape Town.

\section{References}

Beder, S. (1992). Getting into deep water: Sydney’s extended ocean sewage outfalls'. In P. 
Scott (Ed.), A herd of white elefants: Australia's Science \& Technlogy Policy (pp. 62-74). Sydney: Hale and Iremonger.

Benaissa, M., Rouane-Hacene, O., Boutiba, Z., Guibbolini-Sabatier, M. E., \& Faverney, C. R. De. (2017). Ecotoxicological impact assessment of the brine discharges from a desalination plant in the marine waters of the Algerian west coast, using a multibiomarker approach in a limpet, Patella rustica. Environmental Science and Pollution Research, 24(31), 24521-24532. http://doi.org/10.1007/s11356-017-0081-4

Bennett, S., Wernberg, T., Connell, S. D., Hobday, A. J., Johnson, C. R., \& Poloczanska, E. S. (2015). The "Great Southern Reef”: social, ecological and economic value of Australia' s neglected kelp forests. Marine and Freshwater Research, 67, 47-56. http://doi.org/http://dx.doi.org/10.1071/MF15232

Blue Flag. (2013). Blue Flag Programme: eco-label for beaches and marinas. Retrieved September 8, 2013, from www.blueflag.org

Bonney, R., Cooper, C. B., Dickinson, J., Kelling, S., Phillips, T., Rosenberg, K. V., \& Shirk, J. (2009). Citizen Science: A Developing Tool for Expanding Science Knowledge and Scientific Literacy. BioScience, 59(11), 977-984. http://doi.org/10.1525/bio.2009.59.11.9

Bradfield, L. (2015). City of Cape Town still mum over sewage infested ocean. The South African. Retrieved from http://www.thesouthafrican.com/city-of-cape-town-still-mum-over-sewage-infested-ocean/

Cohen, M. (2017). Will Cape Town run out of water? Bloomberg Climate Changed. Retrieved from https://www.bloomberg.com/news/features/2017-12-08/will-cape-town-run-out-of-water Connell, S. D., Russell, B. D., Turner, D. J., Shepherd, S. A., Kildea, T., Miller, D., ... Cheshire, A. (2008). Recovering a lost baseline: Missing kelp forests from a metropolitan coast. Marine Ecology Progress Series, 360, 63-72. http://doi.org/10.3354/meps07526

CSIR. (2017). Cape Town outfalls monitoring programme. Surveys made in 2015/2016. Final Report June 2017. City of Cape Town.

DeFlorio-Barker, S., Wing, C., Jones, R. M., \& Dorevitch, S. (2018). Estimate of incidence and cost of recreational waterborne illness on United States surface waters. Environmental Health: A Global Access Science Source, 17(1), 1-10. http://doi.org/10.1186/s12940-017-0347-9

Dickinson, J. L., Zuckerberg, B., \& Bonter, D. N. (2010). Citizen Science as an Ecological Research Tool: Challenges and Benefits. Annual Review of Ecology, Evolution, and Systematics, 41(1), 149-172. http://doi.org/10.1146/annurev-ecolsys-102209-144636

EPA. (2017). National Recommended Water Quality Criteria - Human Health Criteria Table. Retrieved February 13, 2018, from https://www.epa.gov/wqc/national-recommended-water-quality-criteria-human-health-criteria -table 
EU. (2009). EU Bathing Water Quality Directive. Retrieved December 3, 2013, from http://ec.europa.eu/environment/water/water-bathing/pdf/profiles_dec_2009.pdf

Falkenberg, L. J., Burnell, O. W., Connell, S. D., \& Russell, B. D. (2010). Sustainability in near-shore marine systems: Promoting natural resilience. Sustainability, 2(8), 2593-2600. http://doi.org/10.3390/su2082593

Lévesque, B., \& Gauvin, D. (2007). Microbiological guideline values for recreational bathing in Canada: Time for change? The Canadian Journal of Infectious Diseases \& Medical Microbiology = Journal Canadien Des Maladies Infectieuses et de La Microbiologie Médicale / AMMI Canada, 18(2), 153-7. Retrieved from http://www.pubmedcentral.nih.gov/articlerender.fcgi?artid=2533533\&tool=pmcentrez\&rende rtype=abstract

Lusher, J. (1984). Water quality criteria for the South African Coastal Zone. Foundation for Research Development, Council for Scientific and Industrial Research. Retrieved from ISBN 0798832541

Petrik, L., Green, L., Abegunde, A. P., Zackon, M., Sanusi, C. Y., \& Barnes, J. (2017). Desalination and seawater quality at Green Point, Cape Town: A study on the effects of marine sewage outfalls. South African Journal of Science, 113(11-12), 1-10. http://doi.org/10.17159/sajs.2017/a0244

Phakathi, B. (2018, February 5). Farmers lose R14bn as Cape drought bites. Business Day. Retrieved from https://www.businesslive.co.za/bd/economy/2018-02-05-farmers-lose-r14bn-as-cape-drought -bites/

Prinsloo, E. (2015). 50 million litres of raw sewage dumped daily into ocean at Cape Town. Retrieved from https://www.afriforum.co.za/50-million-litres-raw-sewage-dumped-daily-ocean-cape-town/

Rebelo, A. G., Holmes, P. M., Dorse, C., \& Wood, J. (2011). Impacts of urbanization in a biodiversity hotspot: Conservation challenges in Metropolitan Cape Town. South African Journal of Botany, 77(1), 20-35. http://doi.org/10.1016/j.sajb.2010.04.006

Reish, D. J., Oshida, P. S., Mearns, A. J., Ginn, T. C., \& Buchman, M. (2005). Effect of Pollution on Marine Organisms. Water Environment Research, 77(6), 2733-2819. http://doi.org/10.2175/106143015X14338845156380

Shuval, H. (2003). Estimating the global burden of thalassogenic diseases: human infectious diseases caused by wastewater pollution of the marine environment. Journal of Water and Health, 1(2), 53-64. Retrieved from http://www.ncbi.nlm.nih.gov/pubmed/15382734

Stuart, L. (2015). Anthony Turton: Water crisis avoidable. Skills shortages, poor waste management. BIZNEWS. Retrieved from https://www.biznews.com/sa-investing/2015/11/10/antony-turton-water-crisis-avoidable-skill s-shortages-poor-waste-management/ 


\section{Macrothink}

Turton, A. (2015). Sitting on the horns of a dilemma: Water as a strategic resource in South Africa. IRR Liberty, 6(22), 1-26. Retrieved from rr.org.za/reports-and-publications/atLiberty/files/liberty-2013-sitting-on-the-horns-of-a-dilem ma-2013-water-as-a-strategic-resource-in-south-africa

Weimann, E. (2014). Blue Flag Beaches-Bathers at Risk for Thalassogenic Diseases. Journal of Environment and Ecology, 5(1), 38. http://doi.org/10.5296/jee.v5i1.5773

\section{Copyrights}

Copyright for this article is retained by the author(s), with first publication rights granted to the journal.

This is an open-access article distributed under the terms and conditions of the Creative Commons Attribution license (http://creativecommons.org/licenses/by/4.0/) 